\title{
Is Palatal Rugae Pattern a Reliable Tool in Individual Identification in Forensic Odontology Medicine: Descriptive Study in Najran Region
}

\author{
Metwally E Abdalla, Abdel Naser M Emam
}

\begin{tabular}{|c|c|}
\hline & ABSTRACT \\
\hline $\begin{array}{l}\text { KEYWORDS } \\
\text { Rugoscopy, } \\
\text { Palatal rugae, } \\
\text { Measurements, } \\
\text { Shape, } \\
\text { Direction, } \\
\text { Unification. }\end{array}$ & $\begin{array}{l}\text { Getting an identification of a person is still a different and tough process, } \\
\text { particularly in postmortem cases. Sometimes it is imperative to use different tools } \\
\text { suchlike palatal rugae models which yield extremely imperative knowledge and } \\
\text { assistance in a people's identity. Rugoscopy points out to examine the palatal rugae aim } \\
\text { to establish a personal identity. Our research was aimed to analyze the pattern of palatal } \\
\text { rugae in the adult population and the reliability of the palatal rugae. A total of } 128 \\
\text { dental casts were registered in this study, in the age group of } 30-60 \text { year. The casts } \\
\text { examined and marked carefully, based on the classification submitted by Kapali et al. } \\
\text { Measurements of transverse and anteroposterior distance between the first and second } \\
\text { right and left rugae were made using the image Texas Graphic program. The study } \\
\text { showed a specific palatal rugae models in the studied adult people in contrast to other } \\
\text { population's patterns mentioned in the literature. The three measurements; the shape, } \\
\text { the direction and the unification proved that each cast has uniqueness of each rugae } \\
\text { pattern. This proves that study rugae patterns have the potential to identify an } \\
\text { individual. Further, differentiation of rugae length was not considered in our study. } \\
\text { Palatal rugae are considered as a helping technique to get the identity of an individual. }\end{array}$ \\
\hline
\end{tabular}

\section{Introduction}

Identification and distinguishing of an individual is a precondition for death certification. Individual identification is the corner stone of advancement and enlightment. Whether in life or death, the recognition of unknown person has always been crucial to our community. Several scientific techniques are behind individual recognition, such as the impression of fingertip and deoxyribonucleic

\footnotetext{
Metwally E Abdalla

Forensic Medicine and Toxicology Department, Faculty of Medicine, Ismailia, Egypt.

Email: scu.met@gmail.com

Abdel Naser M Emam

Prosthodontic, Department Faculty of Dentistry, Alazhar University, Cairo, Egypt
}

acid matching technique. In some cases it is essential to use uncommon methods, rugroscopy, aim at confirming a person's identity (Kapali et al., 1997).

The palatal rugae (PR) are misaligned, lack of symmetry, and disconnected and eccentric elevation of the mucosa defined in the first third of the palatine, fabricated of the lateral membrane of the incise papilla, organized and coordinated in transverse direction from palatine raphe located in the mild sagittal plane (Darke et al., 2010).The appearance, count and adjustment of rugae pattern of different breeds and sorts are alike in configuration (Buchtova et al., 2003).

Rugae patterns are misaligned, which is a particular advantage of human beings (Stuart 
and Leonard, 2005). The palatal rugae occur across the first four weeks of intrauterine life. They form elevations with a usually take various shapes. The fibers that run anteroposteriorly inside the core and in different curves across the base of each single rugae to form their shape and orientation. Fibroblasts and collage fibers then accumulate in the connective tissue beneath the epithelium to form specific orientation (Amasaki et al., 2003).

It becomes evident that the morphology of rugae is retained the same, however, it has been observed the rugae have grown based on the development of palate. The moment that they are formed, they might encounter changes in their size due to the growth of the palate, however its shape is maintained (Lang and Baumeister, 1984).

Their outline and design are unaltered by environmental insults as high temperature, disorders and irritating substances, or if the rugae are demolished, but reformed on the same location (Kieswetteral., 1996). Moreover, it has been observed the rugae patterns resist alteration for a few days after the person passed away.

It is believed that the rugae pattern resist postmortem changes, because of the protected location in the oral cavity. Moreover, It plays an essential role in individual recognition because of their steadiness, and its singularity for each single person. Limson and Julian pointed out to rugae patterns on their work on recognition or identification of the people, as palatal rugae or rugoscopy (Limson and Julian, 2004).

The rugae pattern as fingertip permission very resistible to external environmental insults for a long period of time because they are so protected. The palatal rugae models are different from each other. Also, it is very specific to every single individual and very steady along the lifelong growth and development (Acharya and Sivapathasund, 2002).

Rugoscopy may be applied and exercised as a recent individual recognition scheme. It could specific and of special interest, in case that the fingertips impression are not available or do not present as in putrefaction and complete charred of the fingers. Furthermore, it is invaluable scientific tool for aviators identity (Caldas et al., 2007).

The basic goal of the work is to examine the palatal rugae models as a helping approach to ascertain or to prove the individuality to each single person.

\section{Material and methods}

To identify the various patterns of rugae model, we have taken and studied a hundred and twenty eight casts, from prosthodontics outpatient clinics, Faculty of Dentistry, Najran University, Saudi Arabia. The maxillary casts of completely or partially edentulous or edentulous patients (males) ranging from 30 to 60 year were examined.

\section{Cast analysis}

A total of 128 dental casts were enrolled in this study, in the age group of 30-60 year. The rugae patterns were determined and identified on each single cast via a $0.3 \mathrm{~mm}$ black form of carbon pencil with sufficient or proper amplification based on the category (Figure2) rendered by (Kapali et al., 1997).

Measurements of transverse and anteroposterior distance between the first and second right and left rugae were made using the UTHSCSA (image Texas Graphic program). Every single cast has imaged through a digital camera with constant and a specified place. The distance between the first and second rugae has been measured on the right and left side. The transverse from left side 
lateral rugae to right side lateral rugae has been measured.

Intact casts with clear rugae area were included. Casts with fissure or any artifacts were excluded. The appearance and pattern of each rugae were categorized (Figure 3 ) to four main kinds: perpendicular, wavy, arch, annular:

1- Perpendicular: invariable in direction, determined by the position of the two points.

2- Wavy: to move backward and forward.

3- Arch: a half moon or loop shape.

4- Annular: the ones that form round or ring shaped.

Direction of each rugae was identified by measuring the corner created by the line connecting its beginning and finishing and the line straight to the median line of the palate. Thus the direction of rugae was categorized (Figure 4) as:

1- Forward: on ward or toward the front to form a positive corner.

2- Backward: turned toward the rear to form a negative corner.

3- Straight: rugae formed no corners.

Unification means two rugae are connected at the beginning or finishing. Therefore, rugae are categorized (Figure 5) as:

1- Diverging: in case that two rugae have one beginning.

2- Converging: In case those rugae have a different beginning at the median raphe, however, they are connected to each other toward the lateral side.

\section{Statistical analysis}

The findings were interpreted via paired t-test to find out differences between the right and left measurements. We have achieved our interpretation by applying Statistical Package for the Social Science version 20.

\section{Results}

To study the different or the various patterns of rugae, we have performed the examination of 128 maxillary casts to measure the $\mathrm{Rt}$ and $\mathrm{Lt}$ anteroposterior and the transverse distance. Examination of the different types of shapes, directions and unification of rugae pattern was performed. Table (1) showed the different measurements of the study. The minimum and the maximum $\mathrm{Rt}$ and $\mathrm{Lt}$ sides anteroposterior distance. Also, the transverse minimum measurement, the maximum distance, the mean and standard deviation were showed.

Table (2) showed the values of each side and the paired differences. Table (3) showed the interpretation of several kinds of palatal rugae. On comparison, several differences in frequencies of rugae and model types were found. The most frequent shape was wavy shape, followed by the curved, straight, and circular shape.

The predominant direction of palatal rugae was the forward direction since it showed a significant difference when compared with backward and perpendicular (straight) directions. Diverging palatal rugae showed a significantly higher incidence than convergence rugae. 
Table (1) : Descriptive statistics of Rt side anteroposterior palatal rugae, Lt side anteroposterior palatal rugae and transverse from left side lateral rugae to right side lateral rugae $(n=128)$ :

\begin{tabular}{|l|c|c|c|c|c|}
\hline \multicolumn{1}{|c|}{ Variable } & Minimum & Maximum & Mean & $\begin{array}{c}\text { Std. Error } \\
\text { Mean }\end{array}$ & SD \\
\hline Rt side anteroposterior rugae & 16.49 & 176.00 & 60.37 & 2.9 & 29.35 \\
\hline Lt side anterorposterior rugae & 17.89 & 122.44 & 54.77 & 1.9 & 22.50 \\
\hline Transverse & 144 & 286.4 & 242.16 & & 38.62 \\
\hline
\end{tabular}

Estimable units are represented in pixels, Rt: right, Lt: left, SD: standard deviation.

Table (2): Paired samples test between Rt side and Lt side anteroposterior distances

\begin{tabular}{|c|c|c|c|c|c|}
\hline \multirow{2}{*}{} & \multicolumn{5}{|c|}{ Paired Differences } \\
\cline { 2 - 6 } & Std. Deviation & Std. Error Mean & $\mathrm{T}$ & $\mathrm{Df}$ & Sig.(2- tailed) \\
\hline \multirow{2}{*}{ Rt - left } & 21.23947 & 1.87732 & 2.97 & 127 & 0.003 \\
\hline
\end{tabular}

Table (3): Descriptive statistics of different types of palatal rugae.

\begin{tabular}{|c|c|c|c|c|c|}
\hline \multicolumn{2}{|l|}{ Parameters } & Number & $\%$ & Mean & $\mathrm{SD}$ \\
\hline & Total & 631 & & & \\
\hline \multirow{4}{*}{ Shape } & Wavy & 245 & 38.8 & 8.4 & 0.9 \\
\hline & Curved & 205 & 32.4 & 3.4 & 1.05 \\
\hline & Straight & 157 & 24.8 & 2.8 & 1.09 \\
\hline & Circular & 24 & 3.8 & 1.4 & 0.48 \\
\hline \multirow{3}{*}{ Direction } & Backward & 182 & 28.8 & 4.8 & 1.01 \\
\hline & Forward & 235 & 37 & 2.7 & 0.8 \\
\hline & Perpendicular & 104 & 16.4 & 1.9 & 0.6 \\
\hline \multirow{2}{*}{ Unification } & Diverging & 134 & 21 & 1.05 & 0.5 \\
\hline & Converging & 116 & 18 & 0.9 & 0.4 \\
\hline
\end{tabular}

SD : standard deviation 


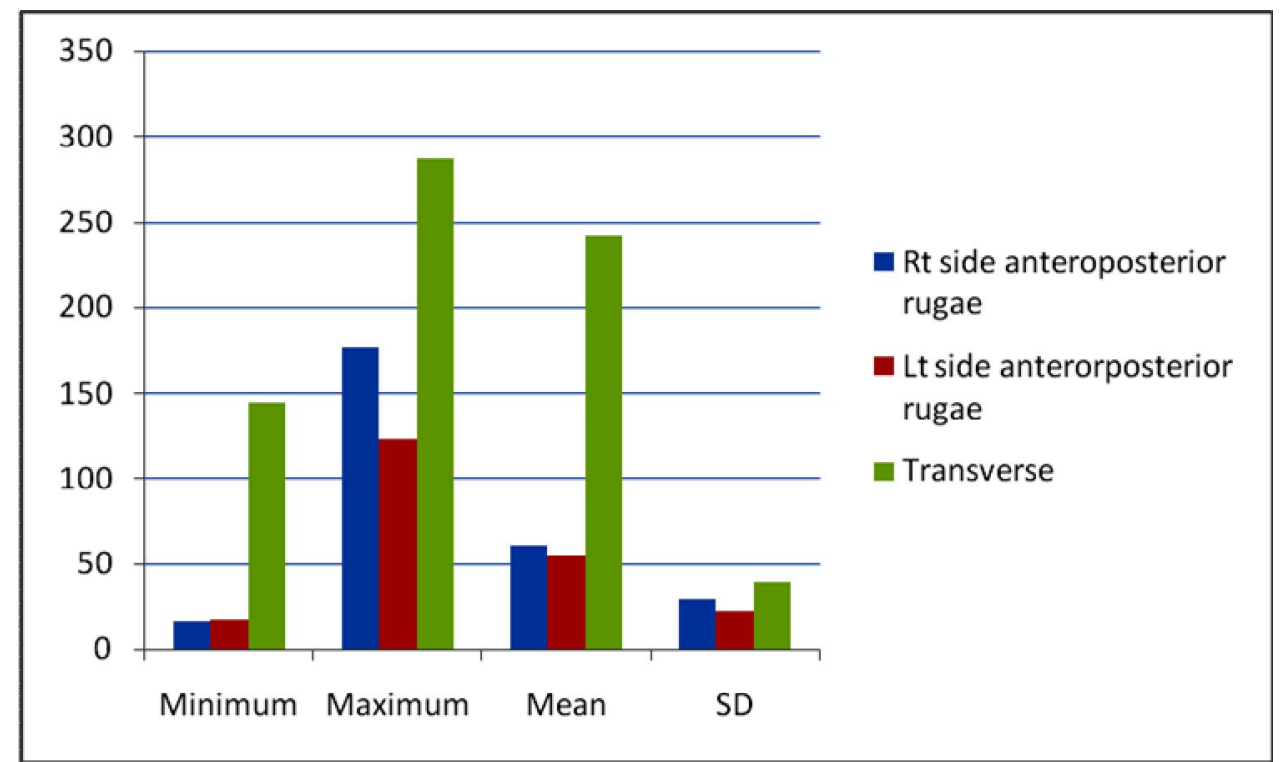

Fig. (1): The minimum, maximum, mean and the standard deviation for the three measures; right, left anteriopestrior and transverse palatal rugae.

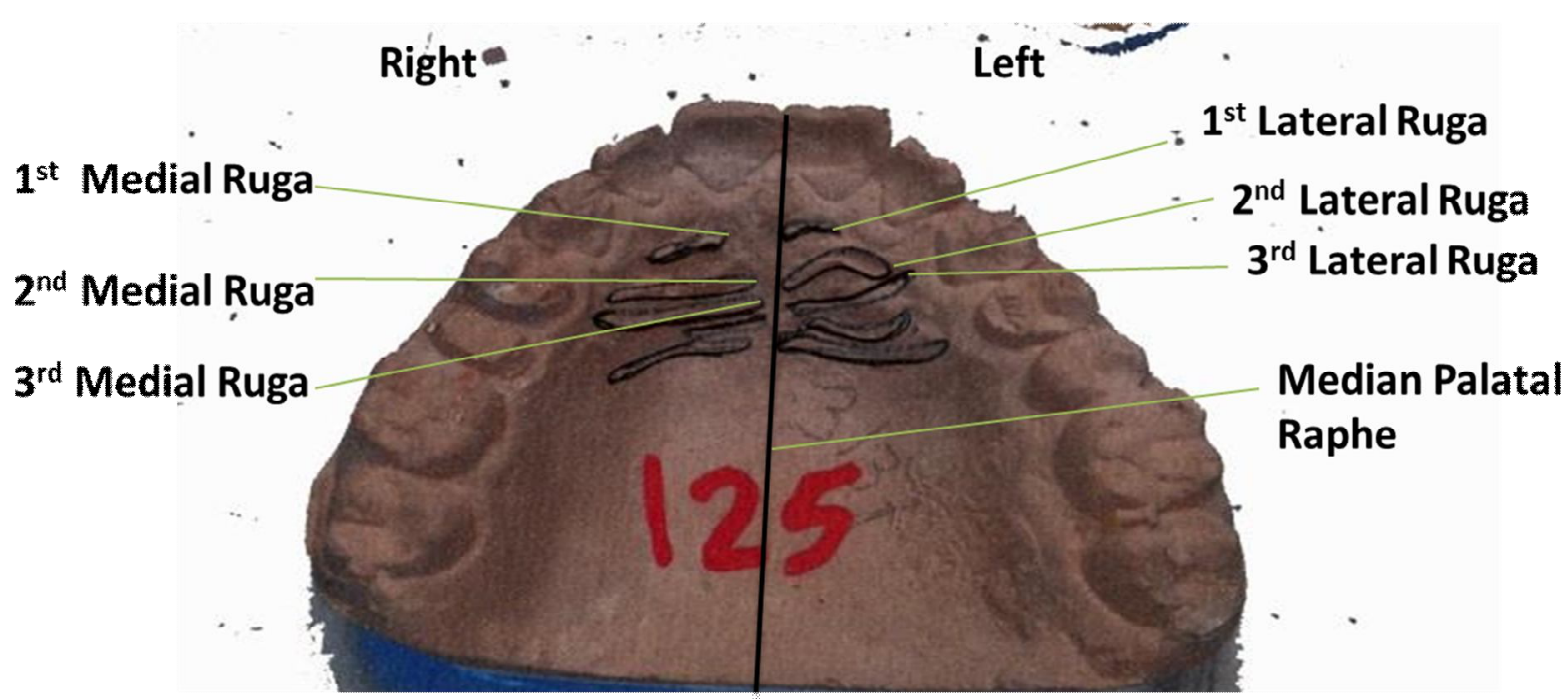

Fig. (2): The rugae pattern is identified and outlined. The right and left rugae are demonstrated. 


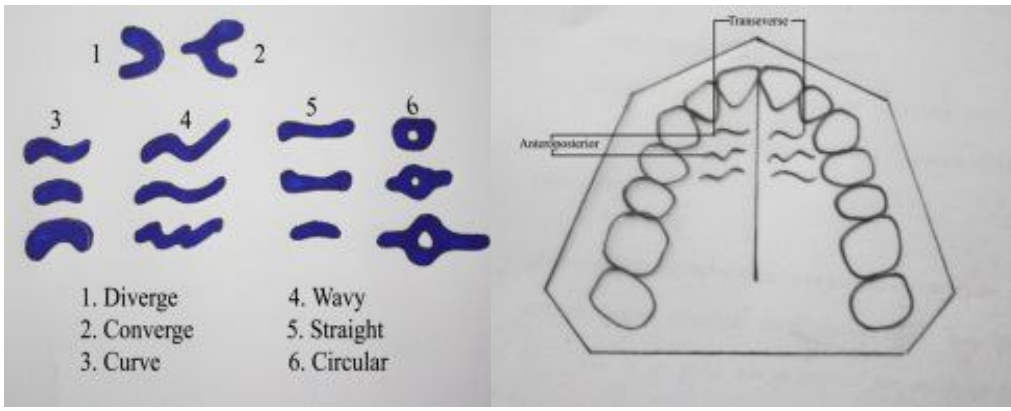

Fig. (3): Various shapes of palatal rugae. Transverse and anteroposterior distances between rugae were shown.

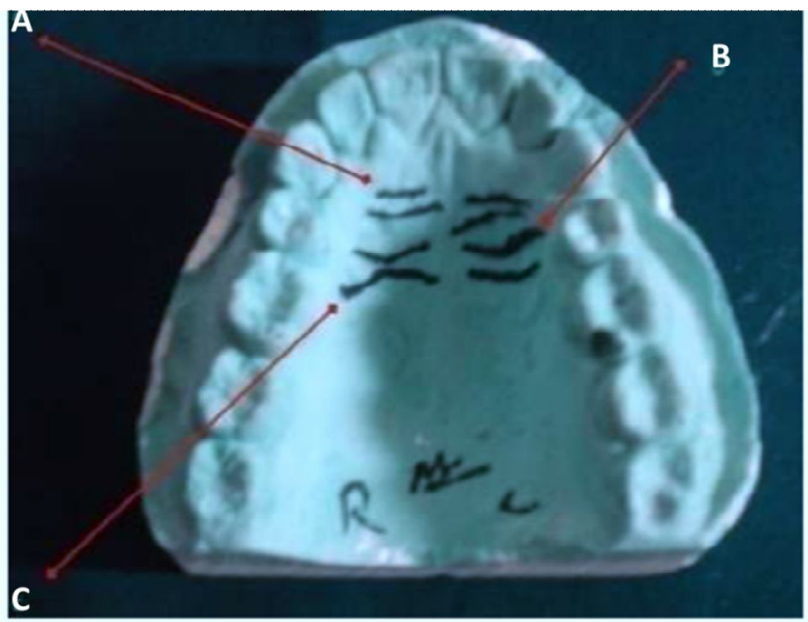

Fig. (4): A photograph of a cast showing: a- perpendicular/straight, b- forward, c- backward directions

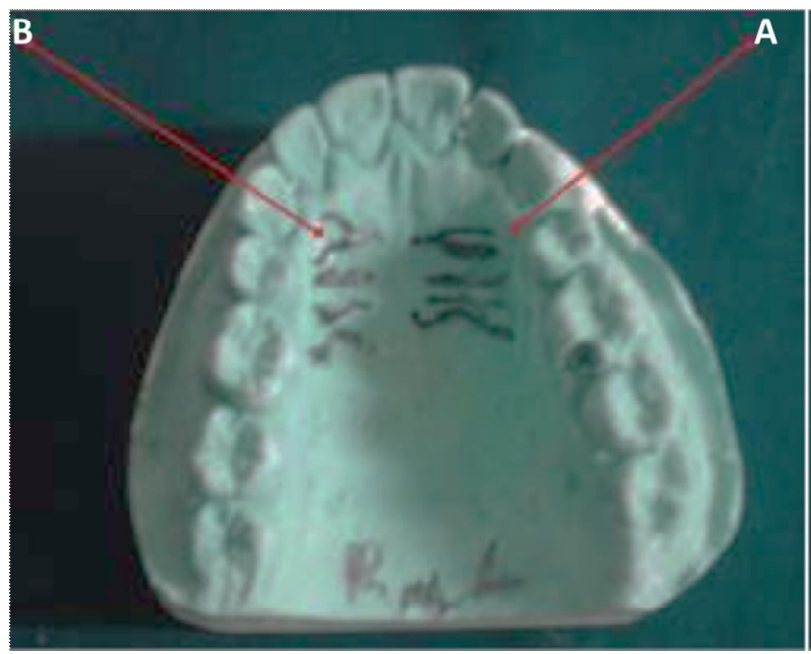

Fig. (5): A photograph of a cast showing: a- diverging rugae, b-converging rugae 


\section{Discussion}

The aim of this work was to examine the patterns of rugae area. Palatal rugae keep their steadiness during dental prosthetics management. Of course, this is due to their steadiness, persistence, and singularity to individuals. Palatal rugae retain their steadiness during prosthodontics techniques and dental implants (Shukla et al., 2011). Accordingly, they equated with fingerprints (Muthusubramanian, 2005).

Many studies stated that inter-racial differences in palatal rugae even in relatively similar population groups. It might identify the population particularly in catastrophes. Our study showed the backward direction was the predominant one. In contrast to the Caldas's study forward rugae direction was the prevailing one relative to the backward one (Caldaset.al., 2007).

Our study showed that, the wavy shape was the prevailing shape followed by curved and straight shape. These findings are close to those rendered by (Abdellatifet al., 2011) who examined the palatine rugae pattern in the Egyptian and Saudi children. Their results concluded that the most widespread palatal rugae form in Egyptians was wavy shape while the curved shape was most common rugae shape in Saudi children, followed by straight rugae.

Additional evidence comes from recent studies found wavy shape as the predominant shape in Caucasian and Aboriginal Australians (Hermosillaet al., 2009) and children population (Eboh, 2012). In contrast, Shubha et al. (2013), observed that the straight shape was the commonest palatal rugae shape followed by wavy shape among the Nigerian population. Our findings found that, forward direction was the predominate direction of palatal rugae. This is in contrast to the Indian population where backward direction was reported to be the predominant direction of the study (Kumar et al., 2012).

Our results showed that presence of the unification rugae pattern in the Saudi population with the diverging form is more prevalent than the converging form. On the contrary to the results reported by (Abdellatif et al., 2011) who compared unification forms of palatal rugae between the Egyptian and Saudi children and stated that, converging rugae were more frequent in Egyptians, while diverging rugae were more frequent in Saudi children.

Contrary to these findings are those observed by previous studies on the Indian population as they found unification rugae pattern to be very rare (Bayatnal et al., 2014). The contrast of rugae models in the African and European populations showed the African had significantly much more numbers of unifications and annular rugae (Nayak et al., 2007).

The differences of rugae patterns have been reported by several comparative studies. This raises the question about the role of both differences in genetic background and environment effects on racial differences. Additional evidence comes from previous studies reported that environment factors are unlikely to affect formation of rugae, and rugae shape is controlled by many genetic factors. This was supported by subsequent twin studies which have revealed that rugae pattern has an underling genetic factor (Gaurav, 2013). 
The orientation of palatal rugae is created by running of collagen fibers anteroposteriorly within the curve and in concentric curves across the base of each rugae. Therefore, in human embryos prominent rugae fill most of the length of palatal structure at the time of their development (Pantalacci, 2008). The process is affected by genetic factors during embryogenesis which may result in variations in rugae pattern between different peoples (Hauser and Dapnte, 1989).

One of the limitations of the study is that it has been conducted only on casts. The second one is that we had not a chance to study the gender (female patients) as a variable, because the outpatient clinics receive only male patients. Additionally, the teaching hospital began to receive patients just two years ago. That is why the sample size is just 128 casts. Furthermore, we had not an opportunity to study the steadiness or credibility of palatal rugae model in persons identify especially after prosthodontics techniques.

An another study indicated that the palatal rugae keep stable during the grow and development, accordingly, it could be applied as reference point for dental interpretation. (Almeida et al.,1995).

One of the misleading factors in the analysis and interpretation of the rugae pattern is the adding of palatal rugae to the palate aim to improve the utterance of vocal sounds (Gitto et al.,1999).

The rugae patterns can be imaged and labeled and kept a data bank to be involved in identity interpretation. And applied in identification cases and confirmed by examining the pairing of photos of palatal rugae pattern.
It could be dedicated that the palatal rugae model might be a helping tool, in addition to different tools in legal techniques.

This study showed a special palatal rugae model in our studied sample, in contrast to other people's pattern that are declared and described in the medical literature.

\section{Conclusion}

We have concluded that the palatal rugae have singularity in shape, direction and unification. In addition, the measurements that we have studied in the study are completely different individually which give uniqueness and have been equated with fingerprints. They are of especial interest in case the fingers are not available as in blazed or complete putrefaction. The protected site of rugae and the singularity to each individual, make it invaluable tool in identification. Of course, if the rugae model is available or casted during the individual's life as a data bank.

\section{Ethical approval}

Necessary ethical approval was obtained from the University Ethics Committee

\section{Acknowledgment}

We deeply appreciate the effort and the time of those who helped us in achieving the work; Dr. Fouad Shohype Professor of Operative Dentistry, Nujran University and Dr. Mustafa Fayad Assistant Professor of Prothodontic, Najran University. Also, we are so grateful for Dr. Abeer Hagras Assistant Professor of Forensic Medicine and Toxicology, Suez canal University for her revision. 
References

Abdellatif, A.M.; Awad, S.M.; Sh.M. (2011):"Hammad Comparative study of palatal rugae shape in two samples of Egyptian and Saudi children". Pediatr. Dent. J., 21 (2): 123-128.

Acharya, A.B.; Sivapathasund H, B. (2006): Forensic odontology: In: Rajen Dram R. Sivapathasund Harm B. Eds. Shafer's Textbook of Oral Pathology, $5^{\text {th }}$ Ed. El Sevier.

Almeida, M.A.; Philips, C.; Kula, K.; Tuloch, C. (1995): "Stability of the palatal rugae as landmarks for analysis of dental casts". Angle Orthod., 65: 4348.

Amasaki, H.; Ogawa, M.; Nagasao, J.; et al. (2003): "Distributional changes of BrdU, PCNA, E2 F1 and PAL31 molecules in developing murine palatal rugae". Ann. Anat, 185: 517-523.

Buchtova, M.; Tichy, F.; Misek, I. (2003): "The development of palatal rugae in the European". Pinevol. Microtussubterraneus Folia Zool, 52: 127136.

Byatnal, A.; Kiran, A.R;Samata, Y.; et al. (2014): "Palatoscopy: An adjunct to forensic odontology: a comparative study among five different populations of India". J. Nat. Sci. Biol. Med., 5(1):52-55.

Caldas, I.M.; Magalhaes, T.; Afonsoo, A (2007): "Establishing identity using cheiloscopy and palatoscopy". Forensic Sci. Int., 165:1-9.

Darke, R.L.; Vogel A.W.; Mitchelle, A.W.M. (2010): Roof-Palate, In, Gray's Anatomy for students. 2nd Ed. Canada, Churchell. Livingstone; P.P. 1047-1048.

Eboh, D.E.O. (2012): "Palatal rugae patterns of Urhobos in Abraka, South-Southern
Nigeria". Int. J. Morphol., 30(2):709713.

Gaurav, A. (2013): Cheiloscopy and palatoscopy. In: Textbook of Forensic Odontology. Jaypee. Brothers Medical Publishers, N. Jain (Ed.), Panama, India.

Gitto, C.A.; Esposito, S.J.; Draper, J.M. (1999): "A simple method of adding palatal rugae to a complete denture". J. Prosthet. Dent., 81:237-239.

Hauser, G.; Daponte, A.; Roberts, M.J. (1989): "Palatal rugae". J. Anatomy, 165:237-249.

Hermosilla, V.V.; San Pedro, V.J.; Cantin, M.; Suazo, G.I.C. (2009): "Palatal rugae: systemic analysis of its shape and dimensions for use in human identification". Int. J. Morphol., 27 (3):819-825.

Kapali, S.; Townsend, G.; Richards, L.; Parish, T.(1997): "Palatal rugae patterns in Australian aborigines and Caucasians". Aust. Dent. J., 42:129133.

Kieswetter, K.; Schwartz, Z.; Dean, D.D.; Boyan, B.D. (1996): "The role of important surface characteristics in the healing of bone". Crit. Rev. Oral BioL. Med., 7:329-345.

Kumar, S.; Vezhavendhan, N.; Shanthi, V.; et al. (2012): "Palatal rugoscopy among Puducherry population". J. Contemp. Dent.Pract., 13(3): 401-404.

Lang, J.; Baumeister, R. (1984): "Postnatal development of the width and height of the palate and the palate foramina". Anat. Anz.; 155:151-167.

Limson, K.S.; Julian, R. (2004): "Computarized recording of the palatal rugae pattern and an evaluation of its application in forensic identification". J. Forensic Odontostomatol.; 22:1-4. 
Muthusubramanian, M.; Limson, K.S.; Julian, R. (2005): "Analysis of rugae in burn victims and cadavers to simulate rugae identification in cases of incineration and decomposition". J. Forensic Odontostomatol., 23:26-29.

Nayak, P.; Acharya, A.B.; Padmini, A.T.; Kaveri, H. (2007): "Differences in the palatal rugae shape in two populations of India". Arch. Oral Biol., 52:977982.

Pantalacci, S.; Prochazka, J.; Martin, A.; et al. (2008): "Patterning of palatal rugae through sequential addition reveals an anterior/posterior boundary in palatal development". BMC Dev. Biol., 8:140 .
Shubha, C.; Sujatha, G.P.; Ashok, L.; Santhosh, C.S. (2013): "A study of palatal rugae pattern among North and South Indian population of Davanagere city". J. Indian Acad. Forensic Med., 35 (3):219-222.

Shukla, D.; Chowdhry, A.; Bablani, D.; et al. (2011): "Establishing the reliability of palatal rugae pattern in individual identification (following orthodontic treatment)". J. Forensic Odontostomatol., 29(1):20-29.

Stuart, L.S.; Leonard, G. (2005): Forensic application of palatal rugae in dental identification. In: Missouri: The Forensic Examiner, Spring. P.P. 44-47. 

هل بصمة روجي بالفك العلوي أداة فعالة في التعرف على الفرد في الطب الشرعي وطب الأسنان: دراسة

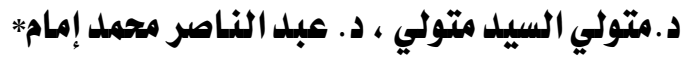

مدرس الطب الثرعي والسموم- كلية الطب جامعة قناة السويس

*أستاذ مساعد طب الأسنانجامعة الأزهر. وأستاذ مشارك بطب الأسنان(التركيبات) جامعة نجران بالسعودية

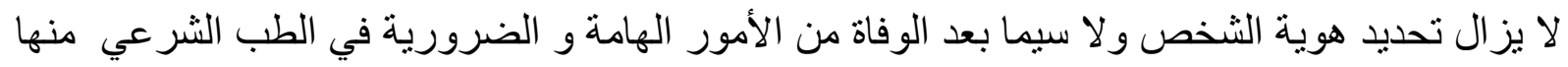

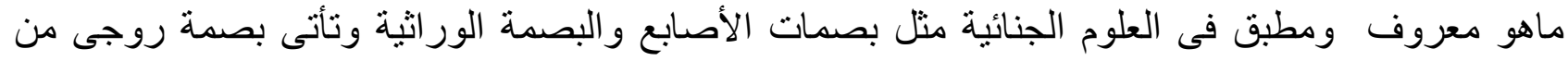

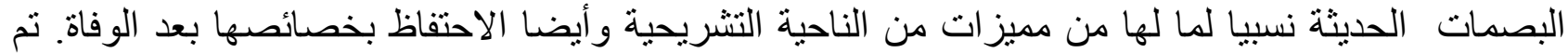

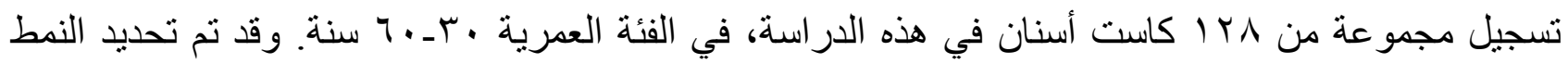

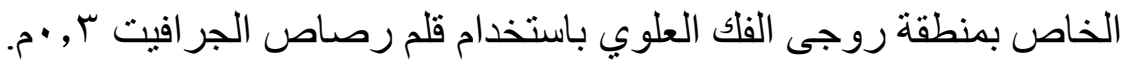

وتم أخذ القياسات باستخدام تقنية مركز العلوم الصحية جامعة تكساس في سان أنطونيو أداة الإصدار

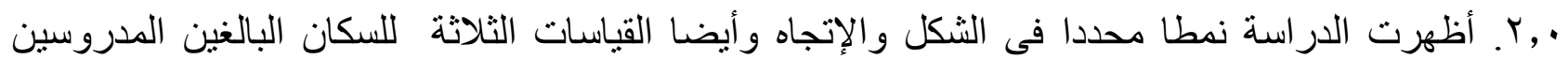

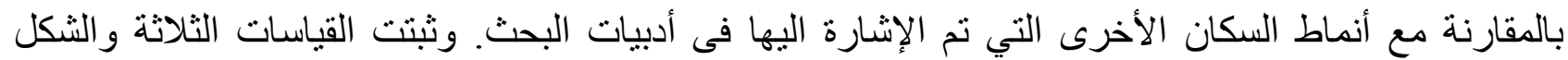

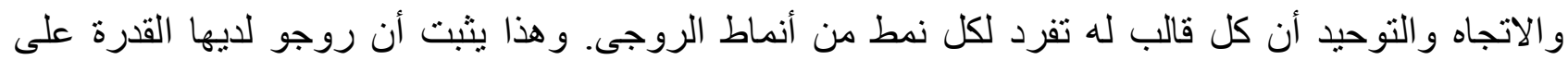

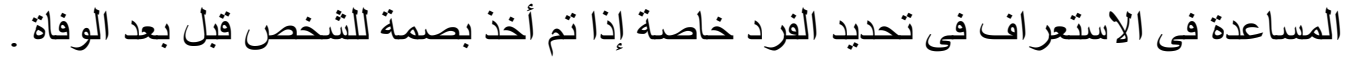

